\title{
Perspectives of nonalcoholic fatty liver disease research: a personal point of view
}

\author{
Amedeo Lonardo ${ }^{1}$ (D), Stefano Ballestri ${ }^{2}$ \\ ${ }^{1}$ Azienda Ospedaliero-Universitaria, Ospedale Civile di Baggiovara, 41125 Modena, Italy \\ ${ }^{2}$ Azienda Usl, Ospedale di Pavullo, 41125 Modena, Italy
}

*Correspondence: Amedeo Lonardo, Azienda Ospedaliero-Universitaria, Ospedale Civile di Baggiovara, 41125 Modena, Italy. a.lonardo@libero.it

Academic Editor: Lindsay A. Farrer, Boston University School of Medicine, USA

Received: April 17, 2020 Accepted: April 27, 2020 Published: June 29, 2020

Cite this article: Lonardo A, Ballestri S. Perspectives of nonalcoholic fatty liver disease research: a personal point of view. Explor Med. 2020:1:85-107. https://doi.org/10.37349/emed.2020.00007

\begin{abstract}
Rational government of patient fluxes from primary care to hepatology clinic is a priority of nonalcoholic fatty liver disease (NAFLD) research. Estimating pre-test probability of disease, risk of fibrosis progression, and exclusion of competing causes of liver disease must be addressed. Here we propose a novel taxonomic classification of NAFLD based on hepatic, pathogenic and systemic features of disease in the individual patient. The variable course of disease in any given patient remains a clinical enigma. Therefore, future studies will have to better characterize the role of genetic polymorphisms, family and personal history, diet, alcohol, physical activity and drugs as modifiers of the course of disease and clues to the early diagnosis of hepatocellular carcinoma. A better understanding of these, together with a taxonomic diagnosis, may prompt a more accurate personalization of care. For example, understanding the putative role of psycho-depression in NAFLD promises to revolutionize disease management in a proportion of cases. Similarly, sex differences in outcome and response to treatment are insufficiently characterized. More studies are awaited regarding those forms of NAFLD which occur secondary to endocrine derangements. The intersections between NAFLD and the lung must better be defined. These include the bi-directional associations of NAFLD and chronic obstructive pulmonary disease and sleep apnoea syndrome, as well as the totally unexplored chapter of NAFLD and coronavirus disease 2019 (COVID-19). Finally, the therapeutic roles of intermittent fasting and anticoagulation must be assessed. In conclusion, over the last 20 years, NAFLD has taught us a lot regarding the pathogenic importance of insulin resistance, the limitations of correcting this in the treatment of NAFLD, the root causes of diabetes and the metabolic syndrome, sex differences in disease and the role of nuclear receptors. However, the overwhelming COVID-19 pandemic is now expected to reset the priorities of public health.
\end{abstract}

\section{Keywords}

Alcoholic fatty liver disease, coronavirus disease 2019, chronic obstructive pulmonary disease, endocrine nonalcoholic fatty liver disease, genetic risk score, liver biopsy, natural history, sex differences 
"The history of a science is that science itself."

-Johann Wolfgang Goethe

\section{Introduction}

\section{Definitions and history}

Nonalcoholic fatty liver disease (NAFLD) is a clinico-pathological syndrome which covers a large gamut of hepatic and extra-hepatic manifestations and complications associated with and predisposing to either individual features of the metabolic syndrome (MetS) [typically type 2 diabetes (T2D) and obesity] or to the full-blown MetS [1-7]. The epidemiological surge of NAFLD is, at least in part, spurious, [i.e. fuelled by our ever increasing ability to discover this common condition in asymptomatic individuals as well as in cases of otherwise "cryptogenic" cirrhosis and hepatocellular carcinoma (HCC)] [8, 9] and, to a larger extent, due to (western-type) lifestyle and lifestyle changes (in developing countries) [10]. Irrespective of this academic contention (spurious phenomenon versus true increase), hard data support the notion that NAFLD accounts for $>30 \%$ of deaths due to liver disease and diabetes and $\sim 8 \%$ of all-cause mortality in the USA [11].

In 1980, Ludwig from the Mayo Clinic, USA, in reporting on 20 patients whose liver biopsies exhibited fatty and necro-inflammatory changes, Mallory bodies, fibrosis and cirrhosis, coined a novel definition consisting of a double composite word: "nonalcoholic steatohepatitis" (NASH) [12]. However, liver disease in the obese had been addressed by Zelman in 1952; in 1977, Haller had already understood that "hepatic steatosis" was a feature of the MetS; what we now call "NASH" was first reported by Thaler from Wien in 1962; what we would now call "NASH-cirrhosis" was first reported in 1979 by Itoh in Japan; in 1988, Diehl defined NAFLD as an "alcohol-like liver disease in the non-alcoholic" and, in 1995, Lonardo et al, in reporting on what they had defined the "bright liver syndrome" highlighted the associations with gallstones and atherosclerosis $[13,14]$. Analysis of the history of NAFLD research has shown that early progress in our understanding of the disease was fostered by individual researchers/groups. However, from 2000 onward, contributions of symposia and scientific societies became prominent [13]. Additional aspects of NAFLD's history have been focused in their excellent article by Fouad et al. [15].

\section{Aims}

The idea behind this narrative review article, based on a 25 -year experience in the study of this disease, is to provide a personal point of view regarding some selected topics of research on NAFLD. To this end, rather than following the "canonical pathway" in writing, which leads to diagnosis and management starting from epidemiology and pathogenesis, specific research questions will be addressed here. This article is not intended to be exhaustive of all the possible topics: to this end, reference should be made to excellent, more systematic reviews [16-19] and scientific society guidelines, which have been compared and annotated elsewhere [20,21]. The present article is principally addressed to clinical and translational investigators but Health Authorities, Ph.D. students, nurses and pharmaceutical industries involved in the active research of innovative drug therapies may also find hints of potential interest here.

\section{Burden and referral patterns}

Mention has previously been made to the true and artefactual determinants underlying the growing clinical and epidemiological importance of NAFLD. Alarming data on the incidence and prevalence of NAFLD pinpoint the necessity of regulating large fluxes of patients from primary practice to consultants and return. The challenges are to allocate the sufficient amount of resources to a condition which is strategically located at the intersection of preventive medicine with clinical medicine. NAFLD fully belongs to the domain of internal medicine given that it is positioned at the crossroad of several medical specialities spanning from hepatology to endocrinology and metabolism and from oncology and cardiovascular medicine to gastroenterology and endoscopy, just to cite some. Active search and identification of individuals at a high risk for NAFLD and regulation of patient fluxes will maintain their key role for proper allocation of resources and maximization of efficacy irrespective of the resources destined to this chapter of public health expenses by each country's 
Health Authorities. On this background, the most logical pathway to follow is to stratify the risk in primary care, with subsequent referrals of those requiring specialist cares [22].

In conclusion, rational regulation and strict government of fluxes from primary (and specialistic such as diabetology) care to hepatology care is a priority of NAFLD research.

\section{Personalized diagnosis}

The key questions in evaluating the individual patient with suspected NAFLD pertain to a) the $a$ priori risk of NAFLD (i.e. pre-test probability of disease) [23, 24]; b) the risk of either advanced or progressive disease (i.e. probability of fibrosis and fibrosis progression) [25]; and c) the exclusion of competing causes of liver disease.

\section{Pre-test probability of disease}

Novel genetic risk scores (GRS) are increasingly being proposed and validated [26-28] to gauge the pre-test probability of NAFLD. However, the use of GRS has a much wider scope spanning further and beyond the simple pre-test assessment of disease [26-31] (Table 1).

Table 1. Gamut of applications of GRS in NAFLD

\begin{tabular}{|c|c|c|c|}
\hline $\begin{array}{l}\text { Author, } \\
\text { year [ref] }\end{array}$ & Method & Finding & Conclusion \\
\hline $\begin{array}{l}\text { Vespasiani- } \\
\text { Gentilucci, } \\
2018 \text { [26] }\end{array}$ & $\begin{array}{l}107 \text { individuals with NASH-cirrhosis, } \\
93 \text { with non-cirrhotic NAFLD, } \\
\text { and } 90 \text { controls were submitted } \\
\text { to genotyping. } \\
\text { A risk score based on SNPs for } \\
\text { the PNPLA3, TM6SF2, and KLF6 } \\
\text { variants was developed. }\end{array}$ & $\begin{array}{l}\text { Compared to a GRS }=0 \text {, a } \\
\text { GRS of } 1-2 \text { was associated with } \\
\text { a 4-fold increased risk, and a } \\
\text { score of 3-4 was associated } \\
\text { with a } 20 \text {-fold increased risk of } \\
\text { having non-cirrhotic NAFLD. } \\
\text { A GRS = 3-4 was associated } \\
\text { with a four-fold increased risk of } \\
\text { NASH-cirrhosis. }\end{array}$ & $\begin{array}{l}\text { A dose-response relationship was } \\
\text { found between increasing GRS and } \\
\text { risk of severe liver disease. }\end{array}$ \\
\hline $\begin{array}{l}\text { Kawaguchi- } \\
\text { Suzuki, } \\
2018 \text { [29] }\end{array}$ & $\begin{array}{l}55 \text { participants of an RCT on long- } \\
\text { term pioglitazone treatment in NASH } \\
\text { were enrolled. } \\
\text { Primary outcome defined as } \geq 2 \text {-point } \\
\text { reduction of NAS. } \\
\text { SNPs in putative candidate genes } \\
\text { were evaluated. } \\
\text { A genetic response score was } \\
\text { developed based on the sum of } \\
\text { response alleles for selected genes. }\end{array}$ & $\begin{array}{l}\text { The genetic response score } \\
\text { was significantly associated } \\
\text { with achievement of the } \\
\text { primary outcome. }\end{array}$ & $\begin{array}{l}\text { Genetic factors account for a } \\
\text { fraction of the inter-individual } \\
\text { variability in response to pioglitazone } \\
\text { administration in NASH patients. }\end{array}$ \\
\hline $\begin{array}{l}\text { Ma, } 2018 \\
{[30]}\end{array}$ & $\begin{array}{l}1521 \text { participants of the 3rd- } \\
\text { generation cohort of the Framingham } \\
\text { Heart Study were enrolled. } \\
\text { Dietary intake was assessed with the } \\
\text { self-administered semi-quantitative } \\
\text { 126-item Harvard food frequency } \\
\text { questionnaire. Diets were scored } \\
\text { based on either the MDS or the AHEI. } \\
\text { The extent of steatosis was assessed } \\
\text { using CT images. } \\
\text { Weighted GRS for NAFLD was } \\
\text { determined based on multiple SNPs } \\
\text { identified in GWAS of NAFLD. }\end{array}$ & $\begin{array}{l}\text { Higher GRS were associated } \\
\text { with increased steatosis in } \\
\text { individuals who had decreased } \\
\text { MDS or AHEI scores, but not in } \\
\text { those with stable or improved } \\
\text { diet scores. }\end{array}$ & $\begin{array}{l}\text { Dietary improvements are particularly } \\
\text { recommendable to those who are } \\
\text { at a high genetic risk for developing } \\
\text { NAFLD. }\end{array}$ \\
\hline
\end{tabular}


Table 1. Gamut of applications of GRS in NAFLD (continued)

\begin{tabular}{|c|c|c|c|}
\hline $\begin{array}{l}\text { Author, } \\
\text { year [ref] }\end{array}$ & Method & Finding & Conclusion \\
\hline $\begin{array}{l}\text { Danford, } \\
2018 \text { [31] }\end{array}$ & $\begin{array}{l}177 \text { individuals with biopsy-proven } \\
\text { NAFLD were recruited. } \\
\text { The eLP-IR index was calculated } \\
\text { based on serum biomarkers } \\
\text { using MRS. } \\
\text { Genetic score - Individuals who } \\
\text { had neither allele of PNPLA3 } \\
\text { and TM6SF2 received a } 0 \text { score. } \\
1 \text { point was assigned for either } \\
\text { heterozygotes or homozygotes of } \\
\text { NPLA3 and TM6SF2 minor alleles. } \\
\text { A score of } 2 \text { was assigned to those } \\
\text { who had } \geq 1 \text { allele of both PNPLA3 } \\
\text { and TM6SF2 minor alleles. }\end{array}$ & $\begin{array}{l}\text { The combination of eLP-IR } \\
\text { with the genetic score and age } \\
\text { accurately predicted advanced } \\
\text { stages of fibrosis (stages } 3-4 \\
\text { liver) with an AUROC }=0.82 \text {. }\end{array}$ & $\begin{array}{l}\text { A study supporting the notion that } \\
\text { genetic and metabolic drivers dictate } \\
\text { the severity of NAFLD as well as } \\
\text { indicating a novel risk stratification } \\
\text { based on pathogenic determinants } \\
\text { of disease. }\end{array}$ \\
\hline $\begin{array}{l}\text { Di Costanzo, } \\
2019 \text { [27] }\end{array}$ & $\begin{array}{l}230 \text { obese Italian children underwent } \\
\text { metabolic assessment and evaluation } \\
\text { of gene polymorphisms (PNPLA3, } \\
\text { TM6SF2, GCKR, and MBOAT7). } \\
\text { HFF\% was assessed with MR. }\end{array}$ & $\begin{array}{l}\text { HFF\% was accounted for by } \\
\text { anthropometric and metabolic } \\
\text { variables (BMI, HOMA-IR, } \\
\text { MetS, transaminases, GGT } \\
\text { and albumin) for } 8.7 \% \text {. And by } \\
\text { genetic factors for } 16.1 \% \text {. } \\
\text { A weighted-GRS (combining } \\
\text { PNPLA3, GCKR, and TM6SF2 } \\
\text { risk alleles) was associated } \\
\text { with an approximately eight-fold } \\
\text { increased NAFLD risk. }\end{array}$ & $\begin{array}{l}\text { Genetic factors play a key role in } \\
\text { the determinism of intra-hepatic fat } \\
\text { content in obese Italian children. }\end{array}$ \\
\hline $\begin{array}{l}\text { Zusi, } \\
2019 \text { [28] }\end{array}$ & $\begin{array}{l}\text { A GRS was developed taking } \\
\text { into account the SNPs of GCKR, } \\
\text { MBOAT7, GPR120, SOD2, PNPLA3, } \\
\text { TM6SF2, LPIN1, ELOVL2, FADS2, } \\
\text { MTTP and KLF6 as well as clinical } \\
\text { risk factors in a cohort of } 514 \text { obese } \\
\text { children and adolescents. } \\
\text { NAFLD was diagnosed with US. }\end{array}$ & $\begin{array}{l}\text { By adding a 11-polymorphism } \\
\text { GRS, the accuracy of the } \\
\text { statistical model for predicting } \\
\text { the risk of NAFLD was } \\
\text { significantly (albeit modestly) } \\
\text { improved as compared to a } \\
\text { model evaluating established } \\
\text { clinical risk factors alone. }\end{array}$ & $\begin{array}{l}\text { NAFLD was strongly associated } \\
\text { with three genetic variants, TM6SF2 } \\
\text { rs58542926, PNPLA3 rs } 738409 \text { and } \\
\text { GCKR rs } 1260326 \text { and, more slightly, } \\
\text { with ELOVL2 rs } 2236212 \text {, in obese } \\
\text { children and adolescents. }\end{array}$ \\
\hline
\end{tabular}

AHEI: alternative healthy eating index; AUROC: area under the receiver operating characteristic curve; BMI: body mass index; CT: computed tomography; ELOVL2: ELOVL fatty acid elongase 2; eLP-IR: enhanced lipoprotein IR index; FADS2: Fatty Acid Desaturase 2; GCKR: glucokinase regulator; GGT: gamma-glutamyl-transferase; GPR120: G-protein coupled receptor 120; GWAS: genome-wide association studies of NAFLD; HFF\%: hepatic fat fraction; HOMA-IR: homeostasis model assessment of insulin resistance; KLF6: Kruppel like factor 6; LPIN1: Lipin 1; MBOAT7: Membrane Bound O-Acyltransferase Domain Containing 7; MDS: mediterranean-style diet score; MR: magnetic resonance; MRS: nuclear magnetic resonance spectroscopy; MTTP: microsomal triglyceride transfer protein; NAS: NAFLD activity score; PNPLA3: Patatin-like phospholipase domain-containing protein 3; RCT: randomized controlled trial; SNPs: single nucleotide polymorphisms; SOD2: superoxide dismutase 2; TM6SF2: Transmembrane 6 Superfamily Member 2; US: ultrasound

This research pathway is predicted to gain increasing popularity, not only in paediatric practice, but also in adults, thanks to a growing availability, at cheaper costs, of commercial kits including genetic polymorphisms useful in evaluating the predisposition to developing NAFLD. Besides these tests, which will contribute to expanding our knowledge of the so called "genetic NAFLD", other algorithms will have to be developed and validated to identify the common forms of "metabolic NAFLD". The prototype of such tests, the fatty liver index, originally proposed by Bedogni et al. [32], should probably be reworked through inclusion of at least sex and reproductive status, which are two key modifiers of the risk of NAFLD [33]. In any case, 
direct confirmation of steatosis through imaging techniques, together with the exclusion of competing causes of (steatogenic) liver disease remain a key step in the diagnosis of NAFLD. The type of imaging technique [for example conventional ultrasonography with semi-quantitative indices versus controlled attenuation parameter (CAP) versus magnetic resonance (MR)] will vary as a function of the resources allocated with the more expensive (and accurate) MR imaging predicted to be used more in affluent countries than the cheaper and globally more available ultrasonographic techniques [34].

In conclusion, the most rational (non-invasive) diagnostic approach to NAFLD and its accurate classification in the individual patient are a definite research priority.

\section{Risk of advanced/progressive disease}

Collectively, evidence suggests that NASH, rather than simple steatosis, carries an increased risk of more rapidly progressing to advanced fibrosis/cirrhosis and developing HCC [19, 35]. However, some longitudinal studies have proven that NAFLD is not simply a dichotomous disease (NASH vs. non-NASH). For example, compared to simple steatosis at baseline, which has the lowest risk of disease progression, the presence of even minor degrees of liver injury and inflammation (and perhaps severe steatosis, although in the absence of NASH), is associated with an increased risk of developing significant fibrosis, often in parallel with the deterioration of metabolic comorbidities [36].

A systematic review of ten longitudinal histological studies showed, as early as 2009 , that inflammation was the key predictor of eventual histological fibrosis progression and a rational therapeutic target in NASH [37]. More recently, a European study based on an exploration cohort of 140 individuals with suspected NAFLD and a separate validation cohort of 78 patients with biopsy-proven NASH found that liver fibrosis and NASH were strongly associated with increasing BMI and HOMA-IR [38]. A recent study, by reporting that obesity, either alone or added to alcohol consumption and T2D, is strongly associated with fibrosing liver disease, extends the importance of BMI beyond NAFLD [39]. Together, these studies suggest that fibrosis is the end-result of repeated bouts of hepatic necro-inflammation which, in their turn, are fuelled by metabolic derangements principally resulting from obesity.

Consistently, data from treatment trials support a strong association between histological resolution of steatohepatitis and improvement of fibrosis in NASH patients [40]. Histopathological classification of NASH has traditionally been based on Brunt's criteria and the NAS by Kleiner et al. [41,42]. The NAS, being quantifiable and relatively more reproducible than the diagnosis of definite NASH by Brunt, has largely been used as an endpoint in clinical trials, allowing to semi-quantitatively monitor the severity of NAFLD over time. However, studies suggest that these histopathological classification systems may have distinct clinic-pathological correlations.

Diagnosis of definite NASH according to Brunt's histological criteria has been reported as a stronger predictor of metabolic abnormalities than the NAS score by Kleiner [43-45]. Moreover, studies have shown that-given that it was unable to predict fibrosis progression-NAS was not associated with adverse clinical outcomes in these patients [36].

The new and recently validated histopathological 'Fatty Liver Inhibition of Progression' algorithm and Steatosis, Activity, and Fibrosis (SAF) score have proven to be able to identify NASH patients with distinct clinical (higher prevalence of metabolic risk factors, more severe IR, and higher levels of aminotransferases) and biological (liver fibrosis) profiles of disease severity [38].

Indeed, solid evidence suggests that liver fibrosis dictates the long-term prognosis of NAFLD patients being significantly associated with overall, liver-related and also cardiovascular mortality [46-48].

The identification of subjects with NASH and/or fibrosis is a key topic in the management of NAFLD patients allowing for adequate treatment schedules and follow-up of these patients [49]. Liver biopsy is the reference standard for the diagnosis of liver steatosis with grading/staging of concurrent necro-inflammatory/ fibrotic changes; however, this invasive procedure may be associated with major complications and patient discomfort [50,51]. In addition, it is exposed to the risk of sampling errors and diagnostic inaccuracies as a result of NASH being unevenly distributed throughout the liver tissue [52]. Therefore, it should be reserved 
only to selected patients at risk of progressive liver disease and, of course, cannot be adopted in large epidemiological or interventional studies. On these grounds the research on diagnostic tools for non-invasive and accurate identification of NASH and fibrosis staging is actively ongoing [50, 51, 53, 54].

Clinical scores used for detecting NASH have shown inconsistent results [55]. Biomarkers of fibrosis, such as the NAFLD fibrosis score (NFS), may be adopted in clinical practice to non-invasively screen subjects for the absence or presence of advanced fibrosis, but all of these perform sub-optimally [36, 51]. Subjects with suspected advanced fibrosis or indeterminate scoring should either undergo non-invasive assessment of liver fibrosis with sonoelastographic techniques or be evaluated for liver biopsy [36, 49, 51].

Ultrasound semi-quantitative scores, such as ultrasonographic fatty liver indicator (US-FLI), have shown to be sensitive for liver steatosis as low as $10 \%$ and correlated with anthropometric, metabolic and histological parameters of NAFLD [53, 56, 57]. A US-FLI score $\leq 4$ is quite accurate in ruling out NASH but higher cut-offs performed sub-optimally in differentiating steatosis from NASH [56, 58]. Therefore, this cannot substitute liver biopsy but rather assist in identifying subjects at risk of progressive NASH in whom liver fibrosis severity must be assessed non-invasively by ultrasound-based elastography first and with liver biopsy, when indicated [53]. Studies evaluating the diagnostic performance of ultrasound semi-quantitative scores or new ultrasound quantitative techniques, including CAP and those more recently developed (e.g., backscatter analysis, acoustic structure quantification and speed of sound), coupled with clinical laboratory parameters for detecting NASH are eagerly awaited. MR elastography has shown good accuracy for detecting NASH but it is expensive and its availability is limited [50].

Sonoelastographic techniques, such as transient elastography performed by Fibroscan or acoustic radiation force impulse (ARFI), have shown good accuracy for estimating advanced fibrosis and cirrhosis (F3 and F4 stages), especially if coupled with clinical data, but their accuracy in detecting F1-F2 fibrosis is sub-optimal [50, 51, 59].

Emerging evidence suggests that certain patterns of expression of microRNA (e.g., miR-122, miR-30c, miR-27b/30) are significantly associated with NASH and/or fibrosis, representing ideal candidates to be integrated into prediction algorithms of NAFLD severity [60-62].

In conclusion, future studies should be aimed at evaluating cost-effectiveness and cost-utility ratios of genetic tests and GRSs that also interact with endocrine and metabolic features of the individual patient. Non-invasive diagnostic algorithms based on integrated imaging, liver biomarkers and genetic signature should be devised to accurately detect NASH and, especially, hepatic fibrosis and monitor its changes over time.

\section{Ruling out competing causes of liver disease: how far should we go?}

It is obviously important to carefully exclude those causes of steatosis which are amenable to specific treatment. This is the case, for example, of alcoholic liver disease, hepatitis C virus (HCV) infection and hypothyroidism. Abstinence remains the backbone of treatment of alcoholic liver disease [63]. Effective antiviral cures are available to eradicate HCV [64]. Thyroid replacement therapy has the potential to reverse the pathogenic mechanisms of NAFLD [65]. However, complicating both research and clinical practice, multi-causality may intervene in the development of NAFLD in the individual patient, either at baseline or in the course of follow-up.

Over time, NAFLD has variably been named diabetic hepatitis, alcohol-like liver disease in the non-alcoholic, bright liver syndrome, and insulin-resistance-associated hepatic iron overload [13]. However, given that consensus must be reached on how the diagnosis of NAFLD should be pursued in the individual patient, the very name of NAFLD should give way to more precise definitions, such as proposed by multiple Authors [66-68]. Additionally, in clinical practice and in clinical trials, primary NAFLD (i.e. associated with MetS) should be differentiated from NAFLD deemed to predispose to incident MetS and, ideally, from specific forms of genetic NAFLD and from forms owing to composite etiology (i.e. genetic-and-metabolic) as well as from all the innumerable forms of secondary NAFLD [69].

The rationale for distinguishing alcoholic fatty liver disease (AFLD) from NAFLD was first challenged by Völzke in 2012 [70]. For example, the liver in the obese closely mimics alcoholic liver disease histologically [71, 72]. 
Moreover, the distinction of AFLD from NAFLD is mainly based on specific pathogenic mechanisms. However, alcohol abuse and metabolic disorders associated with obesity often overlap in the same individual and deceptive differences in clinical presentation and outcome are possibly accounted for by selection bias [70]. AFLD and NAFLD also share genetic factors, behavioural/social underpinnings, as well as certain contributors to mortality $[73,74]$. For example, in both conditions, disease is more prevalent in males [74] and both NAFLD [2, 75] and AFLD [76] exhibit prominent extra-hepatic/systemic features. As for the differences between AFLD and NAFLD it has been pinpointed that the advanced stages NAFLD usually present more in older age than AFLD [74]. Regarding laboratory features, the aspartate aminotransferase (AST)/alanine aminotransferase (ALT) $<1$ ratio is more common in NAFLD than AFLD, provided that cirrhosis is absent [74]. To sum up, commonalities between AFLD and NAFLD outnumber distinctions, which supports a shift from artificial categories to a more general approach to fatty liver syndromes as "multi-factorial disorders" [70, 74]. This mutated paradigm is predicted to contribute to improving prevention schedules and assist in exploring more updated nomenclatures and innovative treatment strategies [74].

Academic attention has focused on the risk of NAFLD occurring secondary to rare diseases such as LAL but findings have been inconclusive so far [77].

Further to its etiologic definition, histological characterization of NAFLD should be specified whenever liver biopsy is deemed to be clinically indicated. If liver biopsy is not indicated, non-invasive indices e.g., NFS and fibrosis-4 [78] should be performed, alone or, preferentially, combined with the evaluation of liver stiffness obtained through elastographic (either sono- or MR-based) techniques.

Moreover, a complete work-up of concurrent diseases should be performed based on our present understanding of extra-hepatic manifestations and complications of NAFLD [2]. A proposal for a rational classification of NAFLD based on an extensive diagnostic evaluation of hepatic and extra-hepatic disease is illustrated as follows (Figure 1).

\section{Natural course}

A seminal study has clarified that liver histology is the major determinant of hepatic (as opposed to extrahepatic) course of disease [81]. Another meta-analytical review including 13 studies, enrolling 4, 428 patients with NAFLD (2, 875 of these with NASH) found that, compared to no fibrosis (stage 0), in the subgroup of those who had NASH, the risk of all-cause mortality; liver-related mortality; liver transplantation and liverrelated events increased with worsening fibrosis stage irrespective of age or sex [48]. However, while it is impossible, unnecessary [82], sometimes unethical [83] and unfeasible to propose and perform liver biopsy on all patients who have NAFLD, it is fully conceivable that so far unidentified factors may also contribute to modulate patterns of disease in the individual patient.

For example, the risk factors for the development of HCC in those with NAFLD need to be urgently identified. HCC is the principal cause of mortality in patients with cirrhosis and a leading cause of cancer death worldwide [84]. Early detection of HCC through a surveillance program (defined as screening repeated at pre-fixed intervals of time) may halt its progression via early treatment, thereby reducing mortality from this disease. Ultrasonography, with/without alpha-fetoprotein testing, is accepted as the best available tool for implementing HCC surveillance [50]. NASH-cirrhosis is the strongest risk factor for HCC, but accumulating data suggest that HCC does develop in a significant proportion of NAFLD patients (up to 15-20\%) without histological evidence of cirrhosis, especially if obese/diabetics. A surveillance program is cost-effective in patients with NASH-cirrhosis showing a yearly incidence of HCC ranging between $2.4 \%$ and $12.8 \%$, which is higher than the accepted thresholds for HCC surveillance [85, 86]. Conversely, the absolute risk of HCC in NAFLD, although higher than matched NAFLD-free controls, is too low to recommend a universal HCC surveillance in the whole NAFLD population [86]. Therefore, we need to identify those clinical, laboratory, imaging or genetic-molecular markers for detecting NAFLD patients at high-risk of developing HCC to be selectively surveilled for the early detection of HCC.

In conclusion, future studies will have to better characterize key modifiers of the natural course of NAFLD factors including family and personal history, diet, physical activity and drugs. 


\begin{tabular}{|ll|}
\hline Liver Determinants $\quad$ Extra-hepatic \\
\hline
\end{tabular}

\begin{tabular}{|l|l|}
\hline Extent of Steatosis & $\begin{array}{l}\text { Sex /reproductive } \\
\text { status } \\
\text { Grade of Inflammation } \\
\text { Stage of Fibrosis }\end{array}$ \\
\hline
\end{tabular}

\begin{tabular}{|l|}
\hline Metabolism \\
Cardio-vascular \\
Cancer
\end{tabular}

Figure 1. Articulating the taxonomy of MAFLD. The "LDE" system. Based on archaic suggestions [66] and earlier attempts [67], an international panel including eminent world authorities in NAFLD, none excluded, renamed NAFLD as metabolic associated fatty liver disease (MAFLD) [79]. This proposal now needs to be further articulated in order to fully explore the complexity of disease in the individual patient. The LDE system has a simple structure consisting of a prefix ( $L$ for liver), a central section ( $D$ for determinants) and a suffix (E for extra-hepatic); Liver (L) - We propose that MAFLD should include a prefix illustrating what, in the individual patient, is known about liver involvement. Information regarding this may be achieved, based on clinical judgement, either with non-invasive or biopsy evaluation [36]. Steatosis and inflammation may be classified into mild, moderate or severe and fibrosis as absent (F0), mild (F1-F2) ore advanced (F3-F4). Individuals who have overt cirrhosis and/or HCC should be declared so; Determinants (D) - The importance of sex and reproductive status cannot be overemphasized and genetic determinants, although not requested in all patients with NAFLD (reviewed in 49), must be acknowledged whenever data are available (Table 1). The minimal endocrine assessment in those with NAFLD is to ascertain whether they have either T2D or IR (assessed with HOMA-IR) and whether T2D is associated or not with obesity (i.e. so called "diabesity" [4]. Given its distinct pathogenic features and the possibility to receive specific treatment, hypothyroidism should also be evaluated in all cases [65]. Other types of NAFLD secondary to other endocrine derangements, such as polycystic ovary syndrome (PCOS), growth hormone (GH) deficiency and hypogonadism, should always be declared when the diagnosis is clinically overt [80]; Extra-hepatic (E) - Finally, the systemic nature of NAFLD must be fully illustrated by the suffix "E", which explores and synthesizes data on extra-hepatic manifestations of disease [2]; As an example, illustrating this proposed taxonomy, patient Ms. X.Y. might be declared to have MAFLD (L steatosis mild; inflammation absent; fibrosis absent; D post-menopausal; no SNP identified; associated with hypothyroidism the full-blown MetS; E arterial hypertension; medio-intimal carotid thickening; previous colon cancer). This taxonomy lends itself to being expressed as either a descriptive diagnosis or a score

\section{Personalized management}

Research on novel pharmacological approaches has so far focused on the identification of a "magic bullet", i.e. a drug which benefits all patients. This standard model of treatment (i.e. "one size fits all"), although appealing for commercial and practical reasons, conflicts with the impressive variety of NAFLD pathobiology [87]. Stated otherwise, what needs to be investigated in-depth is a (more) personalized management schedule based on the specific pathobiological features of disease in the individual patient. For example, NAFLD in the subject with either pre-diabetes or T2D should ideally be managed differently from either the nondiabetic individual $[88,89]$ or from the individual who has dyslipidemia alone. NAFLD in the patient who has morbid obesity may indeed be amenable to bariatric surgery [90], but not all NAFLD patients will accept this. Lifestyle modification is universally recommended as the first-line approach for the treatment of NAFLD but adherence to long-lasting calorie restriction is hard to achieve in clinical practice.

\section{Intermittent fasting (IF)}

Conflicting with the large availability of foodstuffs in many countries worldwide, evolution has selected our ability to survive and to adapt to a food-deprived/fasted state [91]. IF defines recurring periods (e.g. 16h to 48h) with little or no energy intake, with intervening periods of normal food intake [91]. IF, together with periodic 
fasting (i.e. IF with periods of fasting or fasting-mimicking diets from 2 to $\geq 21$ days), beneficially affect health and disease processes/states both in experimental conditions and in humans. These favorable effects, which are mediated by activation of adaptive cellular stress response, improved mitochondrial health, DNA repair, autophagy, stem cell-based regeneration as well as enduring metabolic effects, translate into increased longevity and protection from degenerative disease, cardiovascular disease and cancer [91]. IF also protects from the MetS and associated cardio-metabolic disorders [91]. The only study conducted in patients with NAFLD has shown that an alternate-day calorie restriction diet followed for 8 weeks-as compared to usual habit diet-was associated with beneficial effects on BMI, ALT, grade of hepatic steatosis at ultrasonography and fibrosis scores (assessed with ARFI shear wave elastography) with a good adherence level [92]. Further studies are needed to confirm and expand these results.

\section{Endocrine NAFLD/NASH}

Other examples of personalized management protocols may regard those forms of NAFLD which occur secondary to specific endocrine derangements [80]. Furthermore, a deeper understanding of NAFLD pathophysiology in these forms of NAFLD/NASH secondary to endocrine disorders may help in identifying novel therapeutic approaches [65]. For example, a key question is how we may succeed in uncoupling NAFLD from IR [93].

\section{Anticoagulation}

A growing number of patients with NAFLD and progressive liver disease (i.e. NASH-cirrhosis) will be candidates for anticoagulant therapy in the forthcoming years. This prediction is based on the notions that NAFLD/NASH, a globally epidemic condition, is independently associated with an increased risk of abnormalities of cardiac structure/function, including cardiac rhythm disorders such as atrial fibrillation (AF), and also with idiopathic venous thromboembolism (VTE) [94-100]. Accumulating "real world" data suggest that direct oral anticoagulants can be used in AF or VTE patients with advanced chronic liver disease showing similar efficacy and reduced bleeding complications compared to warfarin [99]. An association between inflammation, activation of the coagulation system and the development of hepatic fibrosis and portal hypertension in chronic liver disease has been disclosed by experimental and clinical studies [99, 101]. A protective effect of anticoagulant therapy on the complications of portal hypertension and fibrogenesis has been observed in small sample studies performed in patients with cirrhosis mainly of viral origin [99, 101].

By highlighting that the imbalance between pro-coagulant and anticoagulant activities can also lead to thrombosis, recent evidence has subverted the antique dogma that chronic liver disease represents an acquired bleeding disorder [102]. Stine et al. [103], were first in reporting on the increased risk of portal vein thrombosis in patients with cirrhosis owing to NASH. This is a population in which a more liberal use of oral anticoagulation for preventive and therapeutic purposes will have to be considered. However, given the complex interaction between NAFLD, obesity and body composition; and based on the potential for exercise to beneficially affect all three, additional research is needed to better define the causal role of each in contributing to the pro-thrombotic state of NAFLD in order to improve patient-oriented outcomes [104, 105].

In conclusion, future studies should better define NAFLD in the individual patient (and the taxonomy proposed in Figure 1 may be an example of how this aim may be achieved) in order to guide personalized management aimed at impacting on the liver itself, the disease complications as well as on cardiovascular outcome are eagerly awaited.

The efficacy and long-term feasibility of intermittent fasting need to be evaluated. Although maintenance of life-style changes remains a challenge over the long run, it is worth remembering that even transient remissions of steatosis may metabolically be beneficial [106].

Anticoagulation strategy in patients with cirrhosis is expected to reduce the risk of portal vein thrombosis but, among the bleeding risks, it will obviously be important considering variceal and non-variceal haemorrhage. Cost-utility and risk-benefit ratios of this strategy remain to be evaluated. 


\section{A healthy liver in a healthy mind?}

In general, it comes as contradictory if not frankly paradoxical that NAFLD, which results from unhealthy lifestyle habits, should be managed with pharmacological interventions rather than non-pharmacological approaches $[107,108]$. In this regard, an ancient Roman aphorism states "mens sana in corpore sano" meaning that you will have a healthy mind provided that your body is healthy. This adage was intended to encourage (young) people to engage in physical activity. Further expanding and virtually overturning this concept, it is now also likely that your liver will remain healthy provided that you maintain psychically healthy. For example, poor diet, inadequate physical activity and sedentary behaviour are strongly and independently associated with NAFLD [109]. Of interest, these unhealthy lifestyle habits are also important correlates of psycho-depression [110], suggesting that the latter may be the deep root cause of NAFLD in a proportion of cases. Should this hypothesis be confirmed, it would justify the expectation that management of underlying psychological factors, e.g., through psychological and cognitive-behavioural interventions may eventually promote virtuous lifestyle changes and, in the final analysis, result in the improvement of NAFLD. This rational construct must be evaluated by appropriate studies.

In conclusion, assessing the value, if any, of psychological consultation in the management of carefully selected cases of NAFLD associated with either overt or covert psycho-depressive traits is a research priority. The potential benefits of using anti-depressant drugs in selected NAFLD cases should carefully be balanced versus the risk of increasing body weight and thereby worsening metabolic profile in these patients [111].

\section{NAFLD and sex medicine}

Sex and gender differences are common features of human disease and definite modifiers of the top ten causes of death and morbidity in high-income countries. For example, coronary artery disease exhibits significant differences between men and women in key areas spanning epidemiology, clinical and pathophysiological features, to management and outcome [112]. Moreover, compared to men, women are more spared from infectious as well as chronic inflammatory disease although they are generally more prone to developing autoimmune disorders [113]. Interestingly, these sex differences also regard metabolic disorders and the prevalence of pre-diabetic syndromes is also sexually biased, men exhibiting impaired fasting glucose more often than women whereas impaired glucose tolerance is more prevalent among women than in men [114]. Consistent with all the findings reported above, a robust line of research based on substantial sex differences and the effect of reproductive status in clinical and experimental NAFLD [115-118] has advocated a more widespread awareness of sex differences in NAFLD research [33]. It is widely accepted that the prevalence of disease, as well as its fibrotic progression, follow a sexually dimorphic pattern with men being more exposed to NAFLD than fertile women; however, post-menopausal women lose the protection conferred by estrogen [72, 117, 119, 120]. Owing to the lack of gender/sex consideration in clinical trial design, insufficient data are available regarding sex differences in response to drug treatment of NAFLD $[33,121]$. Weight reduction and regular exercise improve NAFLD, but we do not know how sex and gender affect this [111]. Recent data suggest that engaging in physical activity is associated with a 10\% higher risk reduction of NAFLD in women than in men but, compared to men, women tend to have a lower compliance with recommendations on physical activity [109]. Moderate body weight reduction may suffice to achieve the resolution of NASH in men, while a substantially greater weight loss is necessary for NASH resolution in women [122].

In conclusion, the above-summarized epidemiological background translates into potentially clinically relevant sex differences in outcome and response to treatment [111] which remain, at this moment, largely unexplored.

\section{Endocrine NAFLD}

The notion that hormones regulate body fat distribution and energetic homeostasis implies that deranged hormonal concentrations play a key role in the development of NAFLD [123]. Confirming this pioneer intuition, an innovative line of research has identified a specific role for endocrine disease and hormonal derangements in NASH [124]. Presently, excluding T2D, the most common endocrine disorders associated with NAFLD include PCOS [125], hypothyroidism [126], hypogonadism [80], and GH deficiency [80, 127]. 
In conclusion, more studies are eagerly awaited aimed at gaining a better understanding of NAFLD forms secondary to endocrine derangements, which have been envisaged as a naturally occurring disease model of NAFLD in humans [80]. Therefore, this path of research promises novel therapeutic approaches, which may potentially be exploited also in certain cases of primary NAFLD [80].

\section{Moving across the diaphragm: NAFLD and the lung}

\section{Chronic pulmonary disease}

Epidemiological evidence suggests that chronic lung conditions, such as chronic obstructive pulmonary disease (COPD) and sleep apnoea syndrome, may bi-directionally be associated with either the MetS or its individual components (i.e. diabesity) [128-132].

Mantovani et al. [132], by meta-analyzing six observational studies globally enrolling more than 133, 000 individuals, three quarters of whom were Asians, more than a quarter with NAFLD, observed that NAFLD was significantly associated with reductions of lung volumes at baseline and that such reductions may also be a risk factor for incident NAFLD over follow-up. Not unexpectedly, NAFLD is a risk factor for the development of long-term cardiovascular events and mortality in patients with COPD [133].

As summarized elsewhere [134], studies have illustrated the range of similarities linking COPD and NAFLD which are common non-communicable diseases affected by a genetic predisposition and associated with an unhealthy lifestyle. Moreover, the liver and the lung also have similar vascular anatomy and immune-metabolic functions, such as antigen processing and regulation of energy homeostasis [134]. First-line treatment of COPD and NAFLD includes cessation of smoking, diet and physical activity [134].

In conclusion, COPD and NAFLD are prevalentsystemic diseases with ahigh rate of cardio-nephro-metabolic and cancer co-morbidities and outcomes which, collectively, exact a high health and economic toll. How is it possible that NAFLD and COPD live together? Which is the egg and which is the chicken? Additional studies are warranted in individuals with COPD and NAFLD to address these research questions.

\section{NAFLD and COVID-19}

\section{Clinical vignette}

A 59-year old Caucasian man was admitted to our Medical COVID Unit owing to-severe acute respiratory syndrome coronavirus 2 (SARS-Cov-2) pneumonia. Fever, dysgeusia, nausea, fatigue and polyarthralgia had begun on the 16th of March, a few days following a contact with a definite case of COVID-19. This patient's laboratory profile exhibited IL-6 $240.73 \mathrm{pg} / \mathrm{mL}$ (normal range 0-10), PCR $13.9 \mathrm{mg} / \mathrm{dL}$ (0-0.7), AST 357 U/L (1-37), ALT 354 U/L (1-40), GGT 210 U/L, (18-136), lactate dehydrogenase (LDH) 1242 U/L (208-378), creatine kinase (CK) $400 \mathrm{U} / \mathrm{L}$ (10-170), total bilirubin $0.96 \mathrm{mg} / \mathrm{dL}$ (0.16-1.10), alkaline phosphatase $123 \mathrm{U} / \mathrm{L}$ (38-126), procalcitonin $0.5 \mathrm{ng} / \mathrm{mL}(<0.5)$, prothrombin time/international normalized ratio $1.28(0.80-1.20)$. Competing causes of liver disease and bacterial pneumonia were ruled out. Chest X-rays showed bilateral interstitial pneumonia (Figure 2) and hemogasanalysis disclosed partial pressure of oxygen/fraction of inspired oxygen ratio $=266$.

On the 30th of March, owing to worsening respiratory insufficiency, the patient received non-invasive ventilatory support and was administered oral Hydroxychloroquine and intravenous Tocilizumab at standard doses. Concurrently, laboratory data as well as dyspnea and subjective general conditions improved. The patient was discharged from hospital on the 8th of April.

\section{COVID and the Liver}

While interstitial pneumonia remains the most important, often life-threatening, organ damage occurring in the course of the SARS-Cov-2, liver injury has also been observed in severe cases in full analogy to that observed in the other two closely related highly pathogenic coronaviruses, SARS-CoV and the Middle East respiratory syndrome coronavirus [135]. Prevalence and determinants of altered liver tests are poorly characterized and given their mild and transient nature, and similar to the closely related SARS disease [136] they are expected to be easily overlooked in the setting of prominent respiratory dysfunction and overwhelming pandemic. 


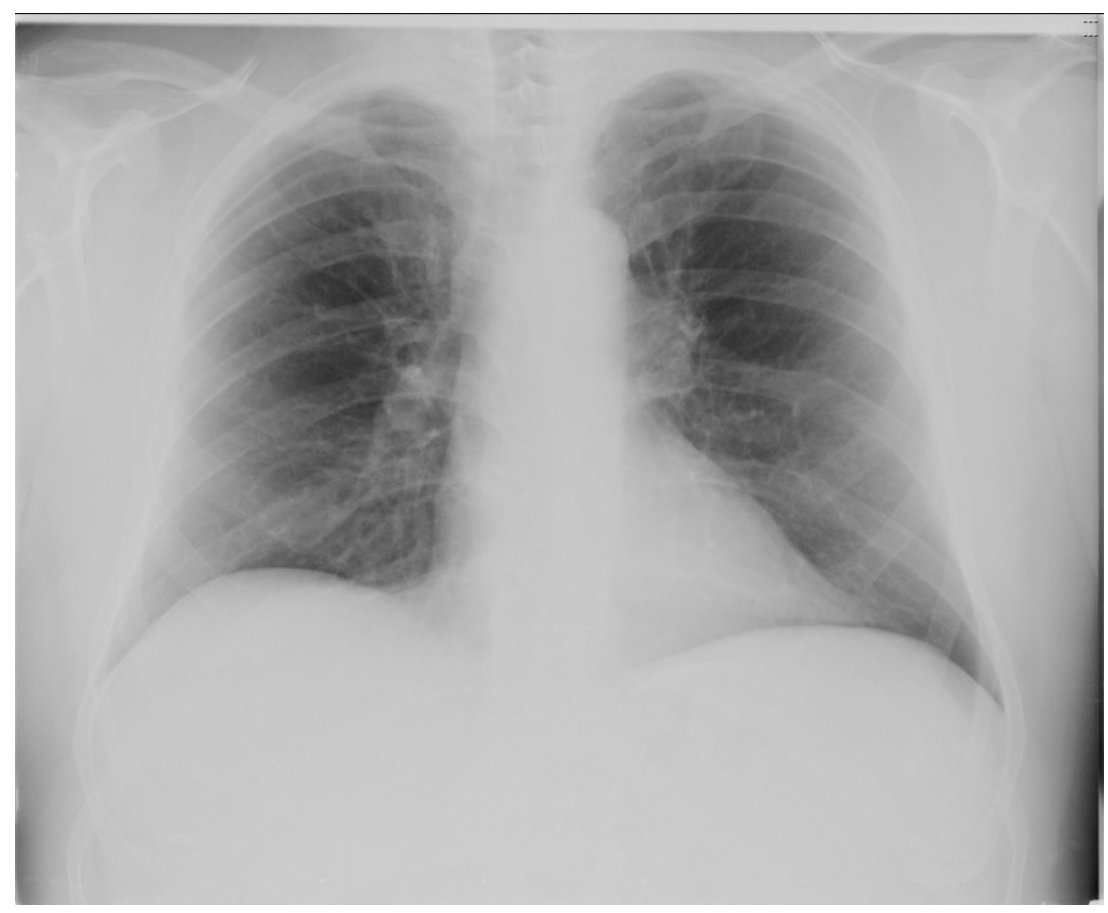

Figure 2. Chest X-Ray in SARS-CoV-2. Chest X-Ray displays a typical bilateral ground glass pattern, which tends to affect the posterior segments of lower lobes, with a peripheral and sub-pleural distribution

A large body of literature indicates that the liver is commonly involved in bacteremia, sepsis and bacterial pneumonia as expressed by altered hepatic enzymes and/or cholestasis [137-143]. However, individuals with COVID-19 pneumonia tend to have remarkably more abnormal values of AST, ALT, GGT and LDH than those with pneumonia owing to non-COVID-19 etiologies [144]. Host and viral factors modulate the risk of liver dysfunction in COVID-19. For example, men and individuals from the highly hyperendemic Wuhan area are deemed to manifest a higher risk of COVID-associated liver dysfunction [145]. Few data are available regarding the pathogenic mechanisms accounting for liver dysfunction in COVID-19 and, speculatively, this may be due to SARS-CoV-2 directly damaging bile duct epithelial cells; concurrent drug-induced liver injury; systemic inflammatory response syndrome; hypoxia-reperfusion dysfunction [145]. It is also reasonable to hypothesize that individuals with pre-existent NAFLD/NASH also display a worse laboratory profile. A recent meta-analysis by Mantovani et al. [146], however, has shown that, while the baseline prevalence of liver disease in patients with COVID-19 is relatively low, major elevations of liver enzymes occur in the course of disease paralleling alterations of coagulative and fibrinolytic pathway profile, as a result of the innate immune response against the virus.

In conclusion, the effects of the SARS-CoV-2 infection on the (fatty) liver are a topic of great clinical and biological interest. Studies will have to ascertain whether liver damage is more common among those with NAFLD/NASH and whether these are exposed to increased mortality. The worse outcome of SARS-CoV-2 infection in those with obesity and increased IL-6 levels may also be a clue to the involvement of the liver $[147,148]$. An additional line of research will have to address what the metabolic complications (including development/progression of NAFLD) will be owing to the protracted physical inactivity (and, in many cases, of perturbed dietary habits) owing to the global lockdown adopted, in many countries, by Health Authorities to combat the COVID epidemic in 2020.

\section{Conclusions}

What is, in its intimate essence, NAFLD? It is an adaptive physiological response [149-151] which, in some cases, becomes maladaptive $[151,152]$ owing to sexual, genetic and environmental modifiers. It is also a barometer of metabolic health $[153,154]$. Therefore, it is illogical to postulate that we should be looking for a pharmacological "magic bullet" which reverses the disease in all cases irrespective of the widely acknowledged [87] individual variability. The intrinsic irrationality of this approach may probably account 
for both the failure of some novel anti-fibrotic drugs such as Cenicriviroc and Selonsertib $[155,156]$ and the only partial success of others which, for example, improve liver histology, though at the cost of worsening the dysmetabolic features (i.e. increased LDL-cholesterol and HbA1c) inherent in the disease [157]. Stated otherwise, we should specifically target those cases of NAFLD with the potential to become progressive over time and diagnosing NASH is a surrogate (not the ultimate) answer to this problem. Simultaneously, the potency of lifestyle in preventing, and reversing the effects of NAFLD [158] needs to be fully appreciated and strongly re-launched thanks to adequate psychological backing and conditioning.

In conclusion, revolutionizing the previously prevailing paradigm of chronic hepatitis owing to viral etiology, over the last 20 years, NAFLD has taught us a lot regarding the pathogenic importance of an endogenous pathogenic factor, insulin resistance $[45,159,160]$ but also the limitations of correcting this in the treatment of NAFLD [161], the root causes of T2D and the MetS [3, 89, 162, 163], the role of sex differences in disease $[33,116,117,164]$ and the key importance of nuclear receptors in determining NAFLD [1]. It is also possible that, thanks to its systemic nature [75] certain features of NAFLD will be exploited in the future for guiding our medical conduct in closely related conditions, such as colo-rectal adenoma and carcinoma, by modulating colonoscopic surveillance programmes based on liver status [165]. That said, the overwhelming COVID-19 pandemic, is now likely to reset the stage of our clinical interest suggesting that-for the time beingNAFLD has probably lost its primacy among contemporary public health issues.

\section{Abbreviations}

AF: atrial fibrillation

AFLD: alcoholic fatty liver disease

AHEI: alternative healthy eating index

ALT: alanine aminotransferase

ARFI: acoustic radiation force impulse

AST: aspartate aminotransferase

AUROC: area under the receiver operating characteristic curve

BMI: body mass index

CAP: controlled attenuation parameter

COPD: chronic obstructive pulmonary disease

COVID-19: Coronavirus disease 2019

CT: computed tomography

ELOVL2: ELOVL fatty acid elongase 2

eLP-IR: enhanced lipoprotein insulin resistance index

FADS2: fatty acid desaturase 2

GCKR: glucokinase regulator

GGT: gamma-glutamyl-transferase

$\mathrm{GH}$ : growth hormone

GPR120: G-protein coupled receptor 120

GRS: genetic risk score

GWAS: genome-wide association studies of nonalcoholic fatty liver disease

HCC: hepatocellular carcinoma

HCV: hepatitis $\mathrm{C}$ virus

HFF\%: hepatic fat fraction

HOMA-IR: homeostasis model assessment of insulin resistance

IF: intermittent fasting 
IR: insulin resistance

KLF6: Kruppel like factor 6

LDH: lactate dehydrogenase

LPIN1: Lipin 1

MAFLD: metabolic associated fatty liver disease

MBOAT7: membrane bound $O$-acyltransferase domain containing 7

MDS: mediterranean-style diet score

MetS: metabolic syndrome

MR: magnetic resonance

MRS: nuclear magnetic resonance spectroscopy

MTTP: microsomal triglyceride transfer protein

NAFLD: nonalcoholic fatty liver disease

NAS: nonalcoholic fatty liver disease activity score

NASH: nonalcoholic steatohepatitis

NFS: NAFLD fibrosis score

PCOS: polycystic ovary syndrome

PNPLA3: patatin-like phospholipase domain-containing protein 3

RCT: randomized controlled trial

SAF: Steatosis, Activity, and Fibrosis

SARS-CoV: severe acute respiratory syndrome coronavirus

SNPs: single nucleotide polymorphisms

SOD2: superoxide dismutase 2

T2D: type 2 diabetes

TM6SF2: transmembrane 6 superfamily member 2

US: ultrasound

US-FLI: ultrasonographic fatty liver indicator

VTE: venous thromboembolism

\section{Declarations}

Acknowledgments

Dedicated to AL's newborn grandson, Amedeo Juhani Lonardo

\section{Author contributions}

$\mathrm{AL}$ and SB together wrote the first draft of the manuscript; equally contributed to manuscript revision, read and approved the submitted version.

\section{Conflicts of interest}

The authors declare that they have no conflicts of interest.

\section{Ethical approval}

Not applicable.

\section{Consent to participate}

Not applicable. 


\section{Consent to publication}

Not applicable.

\section{Availability of data and materials}

Not applicable.

\section{Funding}

Not applicable.

\section{Copyright}

(C) The Author(s) 2020.

\section{References}

1. Ballestri S, Nascimbeni F, Romagnoli D, Baldelli E, Lonardo A. The role of nuclear receptors in the pathophysiology, natural course, and drug treatment of NAFLD in humans. Adv Ther. 2016;33:291-319.

2. Ballestri S, Mantovani A, Nascimbeni F, Lugari S, Lonardo A. Extra-hepatic manifestations and complications of nonalcoholic fatty liver disease. Future Med Chem. 2019;11:2171-92.

3. Ballestri S, Zona S, Targher G, Romagnoli D, Baldelli E, Nascimbeni F, et al. Nonalcoholic fatty liver disease is associated with an almost twofold increased risk of incident type 2 diabetes and metabolic syndrome. Evidence from a systematic review and meta-analysis. J Gastroenterol Hepatol. 2016;31:936-44.

4. Italian Association for the Study of the Liver (AISF). AISF position paper on nonalcoholic fatty liver disease (NAFLD): updates and future directions. Dig Liver Dis. 2017;49:471-83.

5. Lonardo A, Nascimbeni F, Maurantonio M, Marrazzo A, Rinaldi L, Adinolfi LE. Nonalcoholic fatty liver disease: evolving paradigms. World J Gastroenterol. 2017;23:6571-92.

6. Mantovani A, Byrne CD, Bonora E, Targher G. Nonalcoholic fatty liver disease and risk of incident type 2 diabetes: a meta-analysis. Diabetes Care. 2018;41:372-82.

7. Lonardo A, Nascimbeni F, Mantovani A, Targher G. Hypertension, diabetes, atherosclerosis and NASH: cause or consequence? J Hepatol. 2018;68:335-52.

8. Rinaldi L, Nascimbeni F, Giordano M, Masetti C, Guerrera B, Amelia A, et al. Clinical features and natural history of cryptogenic cirrhosis compared to hepatitis $\mathrm{C}$ virus-related cirrhosis. World J Gastroenterol. 2017;23:1458-68.

9. Piscaglia F, Svegliati-Baroni G, Barchetti A, Pecorelli A, Marinelli S, Tiribelli C, et al. Clinical patterns of hepatocellular carcinoma in nonalcoholic fatty liver disease: a multicenter prospective study. Hepatology. 2016;63:827-38.

10. Masarone M, Federico A, Abenavoli L, Loguercio C, Persico M. Non alcoholic fatty liver: epidemiology and natural history. Rev Recent Clin Trials. 2014;9:126-33.

11. Alvarez CS, Graubard BI, Thistle JE, Petrick JL, McGlynn KA. Attributable fractions of NAFLD for mortality in the United States: results from NHANES III with 27 years of follow-up. Hepatology. 2019; [Epub ahead of print].

12. Ludwig J, Viggiano TR, McGill DB, Oh BJ. Nonalcoholic steatohepatitis: Mayo Clinic experiences with a hitherto unnamed disease. Mayo Clin Proc. 1980;55:434-8.

13. Lonardo A, Loria P, Argo C, Caldwell SH. Perspectives on cellular dysfunction in nonalcoholic steatohepatitis: a case of 'multiorganelle failure'? Proceedings of a virtual workshop on nonalcoholic steatohepatitis. Expert Rev Gastroenterol Hepatol. 2011;5:135-9.

14. Lonardo A, Baldelli E. Methodological tools for exploring novel biopharmaceutical approaches to the metabolic syndrome and related disorders: a commentary on: translational research methods in 
diabetes, obesity, and nonalcoholic fatty liver disease. A focus on early phase clinical drug development, second edition. Diabetes Ther. 2020;11:773-7.

15. Fouad Y, Waked I, Bollipo S, Gomaa A, Ajlouni Y, Attia D. What's in a name? Renaming "NAFLD" to "MAFLD". Liver Int. 2020;[Epub ahead of print].

16. Diehl AM, Day C. Cause, pathogenesis, and treatment of nonalcoholic steatohepatitis. N Engl J Med. 2017;377:2063-72.

17. Friedman SL, Neuschwander-Tetri BA, Rinella M, Sanyal AJ. Mechanisms of NAFLD development and therapeutic strategies. Nat Med. 2018;24:908-22.

18. Stefan N, Häring HU, Cusi K. Non-alcoholic fatty liver disease: causes, diagnosis, cardiometabolic consequences, and treatment strategies. Lancet Diabetes Endocrinol. 2019;7:313-24.

19. Cotter TG, Rinella M. Nonalcoholic fatty liver disease 2020: the state of the disease. Gastroenterology. 2020; [Epub ahead of print].

20. Nascimbeni F, Pais R, Bellentani S, Day CP, Ratziu V, Loria P, et al. From NAFLD in clinical practice to answers from guidelines. J Hepatol. 2013;59:859-71.

21. Leoni S, Tovoli F, Napoli L, Serio I, Ferri S, Bolondi L. Current guidelines for the management of nonalcoholic fatty liver disease: a systematic review with comparative analysis. World J Gastroenterol. 2018;24:3361-73.

22. Tsochatzis EA, Newsome PN. Non-alcoholic fatty liver disease and the interface between primary and secondary care. Lancet Gastroenterol Hepatol. 2018;3:509-17.

23. Non-alcoholic Fatty Liver Disease Study Group; Lonardo A, Bellentani S, Argo CK, Ballestri S, Byrne CD, Caldwell SH, et al. Epidemiological modifiers of non-alcoholic fatty liver disease: focus on high-risk groups. Dig Liver Dis. 2015;47:997-1006.

24. Tapper EB, Saini SD, Sengupta N. Extensive testing or focused testing of patients with elevated liver enzymes. J Hepatol. 2017;66:313-9.

25. Younossi ZM, Loomba R, Anstee QM, Rinella ME, Bugianesi E, Marchesini G, et al. Diagnostic modalities for nonalcoholic fatty liver disease, nonalcoholic steatohepatitis, and associated fibrosis. Hepatology. 2018;68:349-60.

26. Vespasiani-Gentilucci U, Dell'Unto C, De Vincentis A, Baiocchini A, Delle Monache M, Cecere R, et al. Combining genetic variants to improve risk prediction for NAFLD and its progression to cirrhosis: a proof of concept study. Can J Gastroenterol Hepatol. 2018;2018:7564835.

27. Di Costanzo A, Pacifico L, Chiesa C, Perla FM, Ceci F, Angeloni A, et al. Genetic and metabolic predictors of hepatic fat content in a cohort of Italian children with obesity. Pediatr Res. 2019;85:671-7.

28. Zusi C, Mantovani A, Olivieri F, Morandi A, Corradi M, Miraglia Del Giudice E, et al. Contribution of a genetic risk score to clinical prediction of hepatic steatosis in obese children and adolescents. Dig Liver Dis. 2019;51:1586-92.

29. Kawaguchi-Suzuki M, Cusi K, Bril F, Gong Y, Langaee T, Frye RF. A genetic score associates with pioglitazone response in patients with non-alcoholic steatohepatitis. Front Pharmacol. 2018;9:752.

30. Ma J, Hennein R, Liu C, Long MT, Hoffmann U, Jacques PF, et al. Improved diet quality associates with reduction in liver fat, particularly in individuals with high genetic risk scores for nonalcoholic fatty liver disease. Gastroenterology. 2018;155:107-17.

31. Danford CJ, Connelly MA, Shalaurova I, Kim M, Herman MA, Nasser I, et al. A pathophysiologic approach combining genetics and insulin resistance to predict the severity of nonalcoholic fatty liver disease. Hepatol Commun. 2018;2:1467-78.

32. Bedogni G, Bellentani S, Miglioli L, Masutti F, Passalacqua M, Castiglione A, et al. The fatty liver index: a simple and accurate predictor of hepatic steatosis in the general population. BMC Gastroenterol. 2006;6:33. 
33. Lonardo A, Nascimbeni F, Ballestri S, Fairweather D, Win S, Than TA, et al. Sex differences in nonalcoholic fatty liver disease: state of the art and identification of research gaps. Hepatology. 2019;70:1457-69.

34. Lonardo A, Marrazzo A, Baldelli E, Nascimbeni F. Noninvasive diagnosis of nonalcoholic fatty liver disease, is the more expensive the better? AME Med J. 2017;2:171.

35. Ekstedt M, Kechagias S, Nasr P, Blomdahl J. Modifiers of liver-related manifestation in the course of NAFLD. Curr Pharm Des. 2020;26:1062-78.

36. Nascimbeni F, Ballestri S, Machado MV, Mantovani A, Cortez-Pinto H, Targher G, et al. Clinical relevance of liver histopathology and different histological classifications of NASH in adults. Expert Rev Gastroenterol Hepatol. 2018;12:351-67.

37. Argo CK, Northup PG, Al-Osaimi AM, Caldwell SH. Systematic review of risk factors for fibrosis progression in non-alcoholic steatohepatitis. J Hepatol. 2009;51:371-9.

38. Nascimbeni F, Bedossa P, Fedchuk L, Pais R, Charlotte F, Lebray P, et al; LIDO (Liver Injury in Diabetes and Obesity) Study Group. Clinical validation of the FLIP algorithm and the SAF score in patients with non-alcoholic fatty liver disease. J Hepatol. 2020;72:828-38.

39. Harris R, Card TR, Delahooke T, Aithal GP, Guha IN. Obesity is the most common risk factor for chronic liver disease: results from a risk stratification pathway using transient elastography. Am J Gastroenterol. 2019;114:1744-52.

40. Brunt EM, Kleiner DE, Wilson LA, Sanyal AJ, Neuschwander-Tetri BA; Nonalcoholic Steatohepatitis Clinical Research Network. Improvements in histologic features and diagnosis associated with improvement in fibrosis in nonalcoholic steatohepatitis: results from the Nonalcoholic Steatohepatitis Clinical Research Network treatment trials. Hepatology. 2019;70:522-31.

41. Brunt EM, Janney CG, Di Bisceglie AM, Neuschwander-Tetri BA, Bacon BR. Nonalcoholic steatohepatitis: a proposal for grading and staging the histological lesions. Am J Gastroenterol. 1999;94:2467-74.

42. Kleiner DE, Brunt EM, Van Natta M, Behling C, Contos MJ, Cummings OW, et al. Design and validation of a histological scoring system for nonalcoholic fatty liver disease. Hepatology. 2005;41:1313-21.

43. Brunt EM, Kleiner DE, Wilson LA, Belt P, Neuschwander-Tetri BA; NASH Clinical Research Network (CRN). Nonalcoholic fatty liver disease (NAFLD) activity score and the histopathologic diagnosis in NAFLD: distinct clinicopathologic meanings. Hepatology. 2011;53:810-20.

44. Ballestri S, Lonardo A, Loria P. Nonalcoholic fatty liver disease activity score and Brunt's pathologic criteria for the diagnosis of non-alcoholic steatohepatitis: what do they mean and do they agree? Hepatology. 2011;53:2142-3.

45. Ballestri S, Nascimbeni F, Romagnoli D, Lonardo A. The independent predictors of non-alcoholic steatohepatitis and its individual histological features.: Insulin resistance, serum uric acid, metabolic syndrome, alanine aminotransferase and serum total cholesterol are a clue to pathogenesis and candidate targets for treatment. Hepatol Res. 2016;46:1074-87.

46. Ekstedt M, Hagström H, Nasr P, Fredrikson M, Stål P, Kechagias S, et al. Fibrosis stage is the strongest predictor for disease-specific mortality in NAFLD after up to 33 years of follow-up. Hepatology. 2015;61:1547-54.

47. Angulo P, Kleiner DE, Dam-Larsen S, Adams LA, Bjornsson ES, Charatcharoenwitthaya P, et al. Liver fibrosis, but no other histologic features, is associated with long-term outcomes of patients with nonalcoholic fatty liver disease. Gastroenterology. 2015;149:389-97.e10.

48. Taylor RS, Taylor RJ, Bayliss S, Hagström H, Nasr P, Schattenberg JM, et al. Association between fibrosis stage and outcomes of patients with nonalcoholic fatty liver disease: a systematic review and metaanalysis. Gastroenterology. 2020;[Epub ahead of print].

49. Lonardo A, LugariS, Nascimbeni F. Non-alcoholic fatty liver disease (NAFLD) diagnosis and managementdifferentiating the essential from the ancillary and the present from the future. HepatoBiliary Surg Nutr. 2019; [Epub ahead of print]. 
50. Ballestri S, Nascimbeni F, Lugari S, Lonardo A, Francica G. A critical appraisal of the use of ultrasound in hepatic steatosis. Expert Rev Gastroenterol Hepatol. 2019;13:667-81.

51. Castera L, Friedrich-Rust M, Loomba R. Noninvasive assessment of liver disease in patients with nonalcoholic fatty liver disease. Gastroenterology. 2019;156:1264-1281.e4.

52. Ratziu V, Charlotte F, Heurtier A, Gombert S, Giral P, Bruckert E, et al. Sampling variability of liver biopsy in nonalcoholic fatty liver disease. Gastroenterology. 2005;128:1898-906.

53. Ballestri S, Tana C, Di Girolamo M, Fontana M, Capitelli M, Lonardo A, et al. Semi-quantitative ultrasonographic evaluation of NAFLD. Curr Pharm Des. 2020;[Epub ahead of print].

54. Wan T, Berzigotti A. Non-invasive assessment of non-alcoholic fatty liver disease: ultrasound and transient elastography. In: Romero-Gomez M, editor. NAFLD and NASH. Cham, Switzerland: Springer International Publishing; 2020. pp. 115-39.

55. Younes R, Rosso C, Petta S, Cucco M, Marietti M, Caviglia GP, et al. Usefulness of the index of NASH ION for the diagnosis of steatohepatitis in patients with non-alcoholic fatty liver: An external validation study. Liver Int. 2018;38:715-23.

56. Ballestri S, Lonardo A, Romagnoli D, Carulli L, Losi L, Day CP, et al. Ultrasonographic fatty liver indicator, a novel score which rules out NASH and is correlated with metabolic parameters in NAFLD. Liver Int. 2012;32:1242-52.

57. Ballestri S, Nascimbeni F, Baldelli E, Marrazzo A, Romagnoli D, Targher G, et al. Ultrasonographic fatty liver indicator detects mild steatosis and correlates with metabolic/histological parameters in various liver diseases. Metabolism. 2017;72:57-65.

58. Nelson SM, Hoskins JD, Lisanti C, Chaudhuri J. Ultrasound fatty liver indicator: a simple tool for differentiating steatosis from nonalcoholic steatohepatitis: validity in the average obese population. J Ultrasound Med. 2020;39:749-59.

59. Petta S, Sebastiani G, Bugianesi E, Viganò M, Wong VW, Berzigotti A, et al. Non-invasive prediction of esophageal varices by stiffness and platelet in non-alcoholic fatty liver disease cirrhosis. J Hepatol. 2018;69:878-85.

60. Pirola CJ, Fernández Gianotti T, Castaño GO, Mallardi P, San Martino J, Mora Gonzalez Lopez Ledesma M, et al. Circulating microRNA signature in non-alcoholic fatty liver disease: from serum non-coding RNAs to liver histology and disease pathogenesis. Gut. 2015;64:800-12.

61. López-Riera M, Conde I, Quintas G, Pedrola L, Zaragoza Á, Perez-Rojas J, et al. Non-invasive prediction of NAFLD severity: a comprehensive, independent validation of previously postulated serum microRNA biomarkers. Sci Rep. 2018;8:10606.

62. Cai C, Lin Y, Yu C. Circulating miRNAs as novel diagnostic biomarkers in nonalcoholic fatty liver disease: a systematic review and meta-analysis. Can J Gastroenterol Hepatol. 2019;2019:2096161.

63. Stickel F, Datz C, Hampe J, Bataller R. Pathophysiology and management of alcoholic liver disease: update 2016. Gut Liver. 2017;11:173-88.

64. Saab S, Le L, Saggi S, Sundaram V, Tong MJ. Toward the elimination of hepatitis C in the United States. Hepatology. 2018;67:2449-59.

65. Lonardo A, Ballestri S, Mantovani A, Nascimbeni F, Lugari S, Targher G. Pathogenesis of hypothyroidism-induced NAFLD: evidence for a distinct disease entity? Dig Liver Dis. 2019;51:462-70.

66. Loria P, Lonardo A, Carulli N. Should nonalcoholic fatty liver disease be renamed? Dig Dis. 2005;23:72-82.

67. Brunt EM. What's in a NAme? Hepatology. 2009;50:663-7.

68. Bellentani S, Tiribelli C. Is it time to change NAFLD and NASH nomenclature? Lancet Gastroenterol Hepatol. 2017;2:547-48.

69. Angulo P. Nonalcoholic fatty liver disease. N Engl J Med. 2002;346:1221-31. 
70. Völzke H. Multicausality in fatty liver disease: is there a rationale to distinguish between alcoholic and non-alcoholic origin? World J Gastroenterol. 2012;18:3492-501.

71. Diehl AM, Goodman Z, Ishak KG. Alcohollike liver disease in nonalcoholics. A clinical and histologic comparison with alcohol-induced liver injury. Gastroenterology. 1988;95:1056-62.

72. Machado M, Marques-Vidal P, Cortez-Pinto H. Hepatic histology in obese patients undergoing bariatric surgery. J Hepatol. 2006;45:600-6.

73. Sanyal AJ, Mathurin P, Nagy LA. Commonalities and distinctions between alcoholic and nonalcoholic fatty liver disease. Gastroenterology. 2016;150:1695-7.

74. Craciun A, Lackner C, Cortez-Pinto H. Nonalcoholic fatty liver disease versus alcohol related liver disease: is it really so different? Curr Pharm Des. 2020; [Epub ahead of print].

75. Petta S, Valenti L, Bugianesi E, Targher G, Bellentani S, Bonino F, et al. A “systems medicine" approach to the study of non-alcoholic fatty liver disease. Dig Liver Dis. 2016;48:333-42.

76. Hayes PC. Extrahepatic manifestations of alcoholic liver disease. Baillieres Clin Gastroenterol. 1993;7:683-96.

77. Carter A, Brackley SM, Gao J, Mann JP. The global prevalence and genetic spectrum of lysosomal acid lipase deficiency: a rare condition that mimics NAFLD. J Hepatol. 2019;70:142-50.

78. Vilar-Gomez E, Chalasani N. Non-invasive assessment of non-alcoholic fatty liver disease: clinical prediction rules and blood-based biomarkers. J Hepatol. 2018;68:305-15.

79. Eslam M, Sanyal AJ, George J; International Consensus Panel. MAFLD: a consensus-driven proposed nomenclature for metabolic associated fatty liver disease. Gastroenterology. 2020;[Epub ahead of print].

80. Lonardo A, Mantovani A, Lugari S, Targher G. NAFLD in some common endocrine diseases: prevalence, pathophysiology, and principles of diagnosis and management. Int J Mol Sci. 2019;20:2841.

81. Vilar-Gomez E, Calzadilla-Bertot L, Wai-Sun Wong V, Castellanos M, Aller-de la Fuente R, Metwally M, et al. Fibrosis severity as a determinant of cause-specific mortality in patients with advanced nonalcoholic fatty liver disease: a multi-national cohort study. Gastroenterology. 2018;155:443-57.

82. Newsome PN, Sasso M, Deeks JJ, Paredes A, Boursier J, Chan WK, et al. FibroScan-AST (FAST) score for the non-invasive identification of patients with non-alcoholic steatohepatitis with significant activity and fibrosis: a prospective derivation and global validation study. Lancet Gastroenterol Hepatol. 2020;5:362-73.

83. Andriulli A, Annese V, Facciorusso D, Giacobbe A. First do no harm: power, oppression, and violence of liver biopsy. Gastroenterology. 2003;125:272-3.

84. Fujiwara N, Friedman SL, Goossens N, Hoshida Y. Risk factors and prevention of hepatocellular carcinoma in the era of precision medicine. J Hepatol. 2018 Mar;68:526-49.

85. White DL, Kanwal F, El-Serag HB. Association between nonalcoholic fatty liver disease and risk for hepatocellular cancer, based on systematic review. Clin Gastroenterol Hepatol. 2012;10:1342-59.

86. Kanwal F, Kramer JR, Mapakshi S, Natarajan Y, Chayanupatkul M, Richardson PA, etal. Risk of hepatocellular cancer in patients with non-alcoholic fatty liver disease. Gastroenterology. 2018;155:1828-37.

87. Suzuki A, Diehl AM. Nonalcoholic steatohepatitis. Annu Rev Med. 2017;14;68:85-98.

88. Vernon G, Baranova A, Younossi ZM. Systematic review: the epidemiology and natural history of non-alcoholic fatty liver disease and non-alcoholic steatohepatitis in adults. Aliment Pharmacol Ther. 2011;34:274-85.

89. Lonardo A, Lugari S, Ballestri S, Nascimbeni F, Baldelli E, Maurantonio M. A round trip from nonalcoholic fatty liver disease to diabetes: molecular targets to the rescue? Acta Diabetol. 2019;56:385-96.

90. Luo RB, Suzuki T, Hooker JC, Covarrubias Y, Schlein A, Liu S, et al. How bariatric surgery affects liver volume and fat density in NAFLD patients. Surg Endosc. 2018;32:1675-82.

91. Mattson MP, Longo VD, Harvie M. Impact of intermittent fasting on health and disease processes. Ageing Res Rev. 2017;39:46-58. 
92. Johari MI, Yusoff K, Haron J, Nadarajan C, Ibrahim KN, Wong MS, et al. A randomised controlled trial on the effectiveness and adherence of modified alternate-day calorie restriction in improving activity of non-alcoholic fatty liver disease. Sci Rep. 2019;9:11232.

93. Yki-Järvinen H. Ceramides: a cause of insulin resistance in NAFLD in both murine models and humans. Hepatology. 2020;71:1499-501.

94. Ballestri S, Lonardo A, Bonapace S, Byrne CD, Loria P, Targher G. Risk of cardiovascular, cardiac and arrhythmic complications in patients with non-alcoholic fatty liver disease. World J Gastroenterol. 2014;20:1724-45.

95. Lonardo A, Ballestri S, Targher G, Loria P. Diagnosis and management of cardiovascular risk in nonalcoholic fatty liver disease. Expert Rev Gastroenterol Hepatol. 2015;9:629-50.

96. Mantovani A, Ballestri S, Lonardo A, Targher G. Cardiovascular disease and myocardial abnormalities in nonalcoholic fatty liver disease. Dig Dis Sci. 2016;61:1246-67.

97. Targher G, Byrne CD, Lonardo A, Zoppini G, Barbui C. Non-alcoholic fatty liver disease and risk of incident cardiovascular disease: a meta-analysis. J Hepatol. 2016;65:589-600.

98. Tana C, Ballestri S, Ricci F, Di Vincenzo A, Ticinesi A, Gallina S, et al. Cardiovascular risk in non-alcoholic fatty liver disease: mechanisms and therapeutic implications. Int J Environ Res Public Health. 2019;16: E3104.

99. Ballestri S, Capitelli C, Fontana Mc, Arioli D, Romagnoli E, Graziosi C, et al. Direct oral anticoagulants in patients with liver disease in the era of non-alcoholic fatty liver disease global epidemic: a narrative review. Adv Ther. 2020; [Epub ahead of print].

100. Targher G, Byrne CD, Tilg H. NAFLD and increased risk of cardiovascular disease: clinical associations, pathophysiological mechanisms and pharmacological implications. Gut. 2020;[Epub ahead of print].

101. Turco L, Schepis F, Villa E. The role of anticoagulation in treating portal hypertension. Curr Hepatol Rep. 2018;17:200-8.

102. Tripodi A, Mannucci PM. The coagulopathy of chronic liver disease. N Engl J Med. 2011;365:147-56.

103. Stine JG, Shah NL, Argo CK, Pelletier SJ, Caldwell SH, Northup PG. Increased risk of portal vein thrombosis in patients with cirrhosis due to non-alcoholic steatohepatitis. Liver Transpl. 2015;21:1016-21.

104. Argo CK, Stine JG, Henry ZH, Lackner C, Patrie JT, Weltman AL, et al. Physical deconditioning is the common denominator in both obese and overweight subjects with nonalcoholic steatohepatitis. Aliment Pharmacol Ther. 2018;48:290-9.

105. Spinosa M, Stine JG. Nonalcoholic fatty liver disease- evidence for a thrombophilic state? Curr Pharm Des. 2020; [Epub ahead of print].

106. Fukuda T, Hamaguchi M, Kojima T, Mitsuhashi K, Hashimoto Y, Ohbora A, et al. Transient remission of nonalcoholic fatty liver disease decreases the risk of incident type 2 diabetes mellitus in Japanese men. Eur J Gastroenterol Hepatol. 2016;28:1443-9.

107. Neuman MG, Nanau RM, Cohen LB. Nonmedicinal interventions in nonalcoholic fatty liver disease. Can J Gastroenterol Hepatol. 2015;29:241-52.

108. Ratziu V. Non-pharmacological interventions in non-alcoholic fatty liver disease patients. Liver Int. 2017;37 Suppl 1:90-6.

109. Kim D, Vazquez-Montesino LM, Li AA, Cholankeril G, Ahmed A. Inadequate physical activity and sedentary behavior are independent predictors of nonalcoholic fatty liver disease. Hepatology. 2020; [Epub ahead of print].

110. Konttinen H, Silventoinen K, Sarlio-Lähteenkorva S, Männistö S, Haukkala A. Emotional eating and physical activity self-efficacy as pathways in the association between depressive symptoms and adiposity indicators. Am J Clin Nutr. 2010;92:1031-9.

111. Jantaratnotai N, Mosikanon K, Lee Y, McIntyre RS. The interface of depression and obesity. Obes Res Clin Pract. 2017;11:1-10. 
112. Regitz-Zagrosek V, Kararigas G. Mechanistic pathways of sex differences in cardiovascular disease. Physiol Rev. 2017;97:1-37.

113. Gubbels Bupp MR. Sex, the aging immune system, and chronic disease. Cell Immunol. 2015;294:102-10.

114. Mauvais-Jarvis F. Gender differences in glucose homeostasis and diabetes. Physiol Behav. 2018;187:20-3.

115. Lonardo A, Trande P. Are there any sex differences in fatty liver? A study of glucose metabolism and body fat distribution. J Gastroenterol Hepatol. 2000;15:775-82.

116. Turola E, Petta S, Vanni E, Milosa F, Valenti L, Critelli R, et al. Ovarian senescence increases liver fibrosis in humans and zebrafish with steatosis. Dis model Mech. 2015;8:1037-46.

117. Ballestri S, Nascimbeni F, Baldelli E, Marrazzo A, Romagnoli D, Lonardo A. NAFLD as a sexual dimorphic disease: role of gender and reproductive status in the development and progression of nonalcoholic fatty liver disease and inherent cardiovascular risk. Adv Ther. 2017;34:1291-326.

118. Salvoza NC, Giraudi PJ, Tiribelli C, Rosso N. Sex differences in non-alcoholic fatty liver disease: hints for future management of the disease. Explor Med. 2020;1:51-74.

119. Halaoui AF, Ali AH, Habib SG, Kanso M, Daniel F, Mukherji DM, et al. Gender differences in liver fibrosis among patients younger than 50 years: a retrospective cohort study. Clin Res Hepatol Gastroenterol. 2020; [Epub ahead of print].

120. Tobari M, Hashimoto E. Characteristic features of nonalcoholic fatty liver disease in japan with a focus on the roles of age, sex and body mass index. Gut Liver. 2020; [Epub ahead of print].

121. Lonardo A, Suzuki A. Sexual dimorphism of NAFLD in adults. Focus on clinical aspects and implications for practice and translational research. J Clin Med. Forthcoming 2020.

122. Vilar-Gomez E, Martinez-Perez Y, Calzadilla-Bertot L, Torres-Gonzalez A, Gra-Oramas B, Gonzalez-Fabian $\mathrm{L}$, et al. Weight loss through lifestyle modification significantly reduces features of nonalcoholic steatohepatitis. Gastroenterology. 2015;149:367-78.

123. Lonardo A, Carani C, Carulli N, Loria P. 'Endocrine NAFLD' a hormonocentric perspective of nonalcoholic fatty liver disease pathogenesis. J Hepatol. 2006;44:1196-207.

124. Loria P, Carulli L, Bertolotti M, Lonardo A. Endocrine and liver interaction: the role of endocrine pathways in NASH. Nat Rev Gastroenterol Hepatol. 2009;6:236-47.

125. Targher G, Rossini M, Lonardo A. Evidence that non-alcoholic fatty liver disease and polycystic ovary syndrome are associated by necessity rather than chance: a novel hepato-ovarian axis? Endocrine. 2016;51:211-21.

126. Mantovani A, Nascimbeni F, Lonardo A, Zoppini G, Bonora E, Mantzoros CS, et al. Association between primary hypothyroidism and nonalcoholic fatty liver disease: a systematic review and meta-analysis. Thyroid. 2018;28:1270-84.

127. Lonardo A, Loria P, Leonardi F, Ganazzi D, Carulli N. Growth hormone plasma levels in nonalcoholic fatty liver disease. Am J Gastroenterol. 2002;97:1071-2.

128. Divo MJ, Casanova C, Marin JM, Pinto-Plata VM, de-Torres JP, Zulueta JJ, et al. COPD comorbidities network. Eur Respir J. 2015;46:640-50.

129. Musso G, Cassader M, Olivetti C, Rosina F, Carbone G, Gambino R. Association of obstructive sleep apnoea with the presence and severity of non-alcoholic fatty liver disease. A systematic review and meta-analysis. Obes Rev 2013;14:417-31.

130. Viglino D, Jullian-Desayes I, Minoves M, Aron-Wisnewsky J, Leroy V, Zarski JP, et al. Nonalcoholic fatty liver disease in chronic obstructive pulmonary disease. Eur Respir J. 2017;49:1601923.

131. Piazzolla G, Castrovilli A, Liotino V, Vulpi MR, Fanelli M, Mazzocca A, et al. Metabolic syndrome and chronic obstructive pulmonary disease (COPD): the interplay among smoking, insulin resistance and vitamin D. PLoS One. 2017;12:e0186708. 
132. Mantovani A, Lonardo A, Vinco G, Zoppini G, Lippi G, Bonora E, et al. Association between non-alcoholic fatty liver disease and decreased lung function in adults: a systematic review and meta-analysis. Diabetes Metab. 2019;45:536-44.

133. Viglino D, Plazanet A, Bailly S, Benmerad M, Jullian-Desayes I, Tamisier R, et al. Impact of non-alcoholic fatty liver disease on long-term cardiovascular events and death in chronic obstructive pulmonary disease. Sci Rep. 2018;8:16559.

134. Lonardo A, Nascimbeni F, Ponz de Leon M. Nonalcoholic fatty liver disease and COPD: is it time to cross the diaphragm? Eur Respir J. 2017;49:1700546.

135. Xu L, Liu J, Lu M, Yang D, Zheng X. Liver injury during highly pathogenic human coronavirus infections. Liver Int. 2020; [Epub ahead of print].

136. Guan YJ, Tang XP, Yin CB, Yi ZQ. Study on the damage of liver in patients with SARS. Zhongguo Wei Zhong Bing Ji Jiu Yi Xue. 2004;16:267-70.

137. Tugwell P, Williams AO. Jaundice associated with lobar pneumonia. A clinical, laboratory and histological study. Q J Med. 1977;46:97-118.

138. Rotenberg Z, Weinberger I, Davidson E, Fuchs J, Sperling O, Agmon J. Significance of isolated increases in total lactate dehydrogenase and its isoenzymes in serum of patients with bacterial pneumonia. Clin Chem. 1988;34:1503-5.

139. Sikuler E, Guetta V, Keynan A, Neumann L, Schlaeffer F. Abnormalities in bilirubin and liver enzyme levels in adult patients with bacteremia. A prospective study. Arch Intern Med. 1989;149:2246-8.

140. Jinks MF, Kelly CA. The pattern and significance of abnormal liver function tests in community-acquired pneumonia. Eur J Intern Med. 2004;15:436-40.

141. Chand N, Sanyal AJ. Sepsis-induced cholestasis. Hepatology. 2007;45:230-41.

142. Jenniskens M, Langouche L, Vanwijngaerden YM, Mesotten D, Van den Berghe G. Cholestatic liver (dys) function during sepsis and other critical illnesses. Intensive Care Med. 2016;42:16-27.

143. Strnad P, Tacke F, Koch A, Trautwein C. Liver-guardian, modifier and target of sepsis. Nat Rev Gastroenterol Hepatol. 2017;14:55-66.

144. Zhao D, Yao F, Wang L, Zheng L, Gao Y, Ye J, et al. A comparative study on the clinical features of COVID-19 pneumonia to other pneumonias. Clin Infect Dis. 2020; [Epub ahead of print].

145. Feng G, Zheng KI, Yan QQ, Rios RS, Targher G, Byrne CD, et al. COVID-19 and liver dysfunction: current insights and emergent therapeutic strategies. J Clin Transl Hepatol. 2020;8:18-24.

146. Mantovani A, Beatrice G, Dalbeni A. Coronavirus disease 2019 and prevalence of chronic liver disease: a meta-analysis. Liver Int. 2020; [Epub ahead of print].

147. Lonardo A, Mantovani A, Lugari S, Targher G. Epidemiology and pathophisology of the association between NAFLD and metabolically healthy or metabolically unhealthy obesity. Ann Hepatol. 2020; [Epub ahead of print].

148. Yang YM, Kim SY, Seki E. Inflammation and liver cancer: molecular mechanisms and therapeutic targets. Semin Liver Dis. 2019;39:26-42.

149. Lonardo A, Lombardini S, Ricchi M, Scaglioni F, Loria P. Review article: hepatic steatosis and insulin resistance. Aliment Pharmacol Ther. 2005;22 Suppl 2:64-70.

150. Yamaguchi K, Yang L, McCall S, Huang J, Yu XX, Pandey SK, et al. Inhibiting triglyceride synthesis improves hepatic steatosis but exacerbates liver damage and fibrosis in obese mice with non-alcoholic steatohepatitis. Hepatology. 2007;45:1366-74.

151. Arrese M. Burning hepatic fat: therapeutic potential for liver-specific thyromimetics in the treatment of nonalcoholic fatty liver disease. Hepatology. 2009;49:348-51.

152. Tsatsoulis A, Mantzaris MD, Bellou S, Andrikoula M. Insulin resistance: an adaptive mechanism becomes maladaptive in the current environment-an evolutionary perspective. Metabolism. 2013;62:622-33. 
153. Chitturi S, Farrell GC. Fatty liver now, diabetes and heart attack later? The liver as a barometer of metabolic health. J Gastroenterol Hepatol. 2007;22:967-9.

154. Rotman Y, Neuschwander-Tetri BA. Liver fat accumulation as a barometer of insulin responsiveness again points to adipose tissue as the culprit. Hepatology. 2017;65:1088-90.

155. Friedman SL, Ratziu V, Harrison SA, Abdelmalek MF, Aithal GP, Caballeria J, et al. A randomized, placebocontrolled trial of cenicriviroc for treatment of nonalcoholic steatohepatitis with fibrosis. Hepatology. 2018;67:1754-67.

156. Harrison SA, Wai-Sun Wong V, Okanoue T, Bzowej N, Vuppalanchi R, Younes Z, et al. Selonsertib for patients with bridging fibrosis or compensated cirrhosis due to NASH: results from randomized phase III STELLAR trials. J Hepatol. 2020; [Epub ahead of print].

157. Hameed B, Terrault NA, Gill RM, Loomba R, Chalasani N, Hoofnagle JH, et al. Clinical and metabolic effects associated with weight changes and obeticholic acid in non-alcoholic steatohepatitis. Aliment Pharmacol Ther. 2018;47:645-56.

158. Farrell GC. Non-alcoholic steatohepatitis: what is it, and why is it important in the Asia-Pacific region? J Gastroenterol Hepatol. 2003;18:124-38.

159. Lonardo A, Loria P, Carulli N. Insulin resistance in non-alcoholic fatty liver disease: a clinical perspective. In: Leuschner U, Dancygier H, James OFW, editors. Steatohepatitis (NASH and ASH). Falk Symposium 121. Dordrecht: Kluwer Academic Publishers Dordrecht; 2001. pp. 104-13.

160. Lonardo A, Loria P, Leonardi F, Borsatti A, Neri P, Pulvirenti M, et al. Fasting insulin and uric acid levels but not indices of iron metabolism are independent predictors of non-alcoholic fatty liver disease. A case-control study. Dig Liver Dis. 2002;34:204-11.

161. Lonardo A, Bellentani S, Ratziu V, Loria P. Insulin resistance in nonalcoholic steatohepatitis: necessary but not sufficient-death of a dogma from analysis of therapeutic studies? Expert Rev Gastroenterol Hepatol. 2011;5:279-89.

162. Lonardo A, Ballestri S, Marchesini G, Angulo P, Loria P. Nonalcoholic fatty liver disease: a precursor of the metabolic syndrome. Dig Liver Dis. 2015;47:181-90.

163. Lonardo A, Ballestri S, Guaraldi G, Nascimbeni F, Romagnoli D, Zona S, et al. Fatty liver is associated with an increased risk of diabetes and cardiovascular disease - Evidence from three different disease models: NAFLD, HCV and HIV. World J Gastroenterol. 2016;22:9674-93.

164. Lonardo A, Suzuki A. Nonalcoholic fatty liver disease: does sex matter? Hepatobiliary Surg Nutr. 2019;8:164-6.

165. Lonardo A, Roncucci L. The "obese liver" and gastrointestinal cancer risk. Transl Gastroenterol Hepatol. 2020;5:44. 